\title{
CLIMATE TRENDS AT MACQUARIE ISLAND AND EXPECTATIONS OF FUTURE CLIMATE CHANGE IN THE SUB-ANTARCTIC
}

\author{
by Neil Adams \\ (with 11 text-figures)
}

\begin{abstract}
Adams, N. 2009 (11:xi): Climate trends at Macquarie Island and expectations of future climate change in the sub-Antarctic. Papers and Proceedings of the Royal Society of Tasmania 143 (1): 1-8. https://doi.org/10.26749/rstpp.143.1.1 ISSN 0080-4 703.

Bureau of Meteorology, GPO Box 727, Hobart, Tasmania 7001, Australia. Email: N.Adams@bom.gov.au
\end{abstract}

\begin{abstract}
Macquarie Island has experienced a marked shift in its climate since 1970, with increasing precipitation, accompanied by a steady increase in mean wind speed associated with increased cyclonic activity. These trends are consistent with an increase in the Southern Annular Mode (SAM) index, albeit with a shift to an anomalous atmospheric trough over the western Pacific Ocean. However, our understanding of the twentieth-century climate across the entire sub-Antarctic is limited by very sparse data and the relatively poor quality of global re-analyses across the Southern Hemisphere. Chapter 10 of the Inter-governmental Panel on Climate Change (IPCC) fourth Assessment Report (AR4) provides an assessment of global atmospheric trends out to the end of the twenty-first century and provides some clues as to the regional trends expected across the sub-Antarctic. This paper provides a synopsis of the changes experienced at Macquarie Island, and a look to future trends, and the need for increased atmospheric research in the mid- to high latitudes of the Southern Hemisphere.
\end{abstract}

Key Words: climate, climate change, Macquarie Island, sub-Antarctic.

\section{INTRODUCTION}

Variability and change in the weather and climate of the sub-Antarctic have received very little attention in the scientific literature. This region of the Southern Hemisphere has its southern boundary near the Antarctic convergence and a somewhat arbitrary northern boundary around $40^{\circ} \mathrm{S}$. Pendlebury \& Barnes-Keoghan (2007) provided a very good synopsis of the climate and climate change science in the subAntarctic but highlighted the very real need for more research. Fyfe (2003) in his modelling study on extra-tropical cyclones in the Southern Hemisphere concluded that the number of cyclones in the sub-Antarctic oceans has been decreasing over the past 50 years, and is projected out to 2100 to continue decreasing, with a continued drying and warming trend for the sub-Antarctic. Chapter 10 of the Inter-governmental Panel on Climate Change (IPCC) fourth Assessment Report (IPCC AR4) (IPCC 2007) also highlighted a significant warming trend across the sub-Antarctic over all seasons. However, precipitation changes were both regionally and seasonally more complex than suggested by Fyfe (2003), with a reduction in sub-Antarctic precipitation limited to more northern latitudes during summer, with winter precipitation generally increasing over most of the sub-Antarctic and in particular in the longitudes of Macquarie Island. One of the problems in drawing conclusions from such broad-scale modelling studies is that the sub-Antarctic spans all longitudes and regional trends may vary significantly. This is compounded by a key limiting factor in the number of long-term meteorological datasets available

FIG. 1 - Sub-Antarctic stations reporting meteorological data. to monitor the sub-Antarctic climate. Figure 1 shows the sparse network of stations dorted across the islands of the subAntarctic, and highlights the complete lack of observational sites directly south of the Australian mainland.

Of the two Australian sub-Antarctic islands, only Macquarie Island has an unbroken meteorological record that stretches back to 1948 , whereas the record for Heard Island is discontinuous, with the bulk of observations limited to surface pressure and temperature. However, the Macquarie Island record offers a wealth of information from which to make comment on climate variability and change on the island and place these in the context of changes within the entire sub-Antarctic region. Furthermore the Macquarie Island weather record is a valuable quantum of

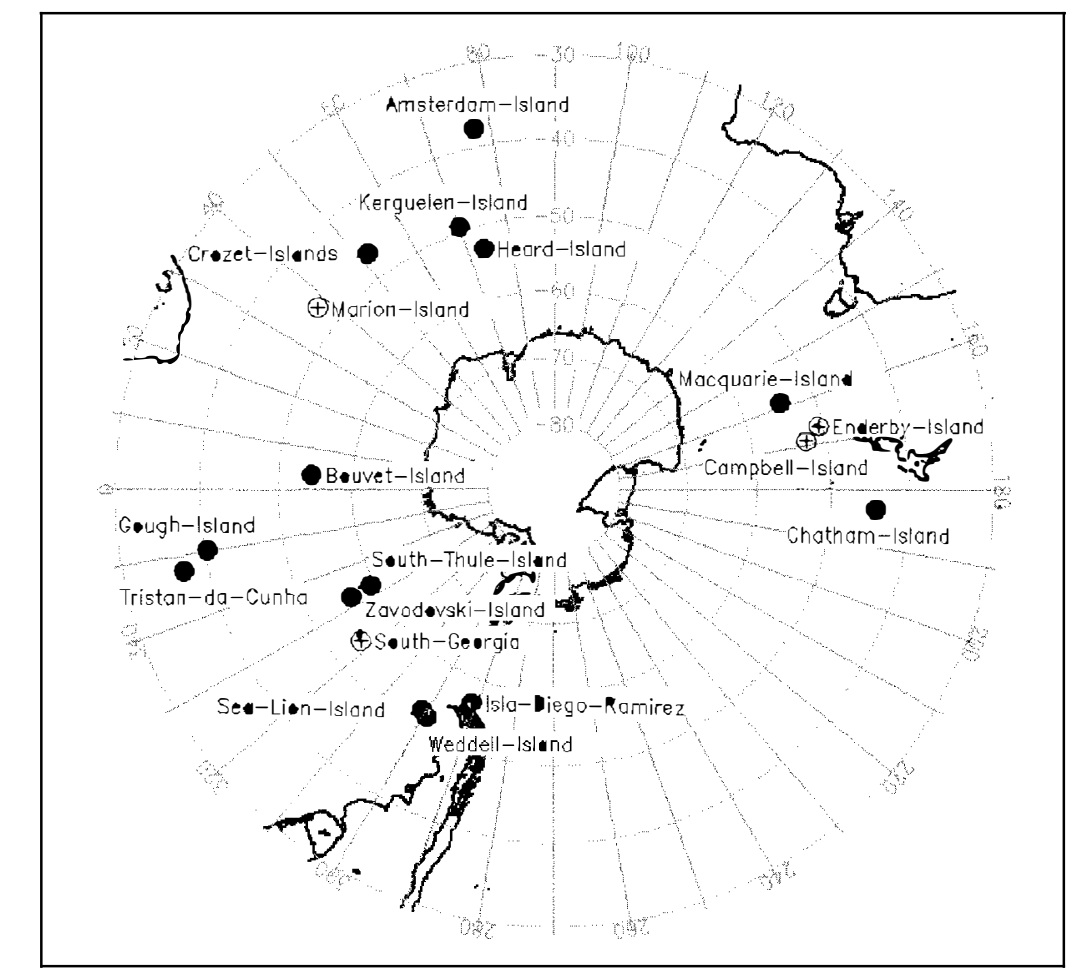


information with which to better understand broad-scale changes seen in the biota of the island itself. Figure 2 shows the annual precipitation totals over the 60-year period from the beginning of records in 1948. In the first two decades of the record a clear reduction in precipitation was observed, followed by a steady and marked increase from around 1970 to the present day, with annual totals over the past decade exceeding those from the beginning of the record. This paper presents an analysis of the meteorological record from Macquarie Island over the 38 years since 1970, places the observed changes within the context of the broader scale changes seen in the sub-Antarctic, and provides a synopsis of some current research into expected changes out to the end of the twenty-first century.

\section{THE MACQUARIE ISLAND RECORD}

The most striking feature of the Macquarie Island meteorological record is the large change in observed rainfall since 1970 . Over the 38 years since then there has been a steady increase in the annual total from around $800 \mathrm{~mm} / \mathrm{a}$ in the very early $1970 \mathrm{~s}$, to around $1080 \mathrm{~mm} / \mathrm{a}$ averaged over the past several years, as highlighted in the top panel of figure 3 . The steady increase since 1970 amounts to about a $35 \%$ increase in precipitation. This striking change is not mirrored in the other meteorological records, with means in the near-surface wind speed, air temperature, dew-point and surface pressure (lower panels in fig. 3) not showing such striking changes. The wind speed record in figure 3 does show a slight increasing trend, and the dew-point has decreased slightly over the record, as has surface pressure, but these changes are subtle and confound any clear explanation of meteorological changes that would explain the dramatic increase in precipitation.

A seasonal breakdown of the meteorological data shows subtle increases in summer (9\%), autumn $(20 \%)$ and spring (28\%) precipitation totals, but with a $55 \%$ increase in winter-time precipitation since 1970 . August monthly totals in precipitation have increased from 1970 by about $120 \%$. It is unlikely that any inhomogeneities in the rainfall observing practices are responsible for the large increases seen since 1970. Alterations in instrumentation or practice could be an explanation for some of these changes. For

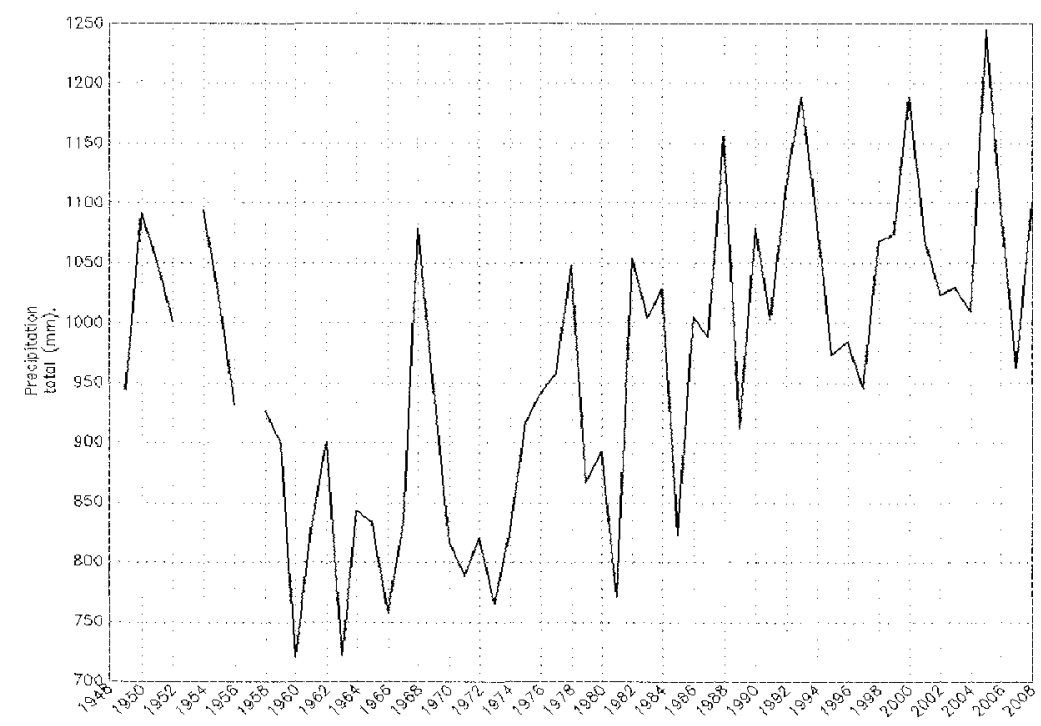

example, in 1995 a snowfall recorder was installed on the island to catch snowfall that overflowed the rainfall recorder. However, it is unlikely that this additional amount of measured precipitation would be large, and there is no obvious signal in the rainfall record around this time. Other possible inhomogeneities are still under investigation (Ian Barnes-Keoghan pers. comm.) but it is not expected that any changes in the rainfall recording are likely to be responsible for the observed increases.

Clearly, the precipitation record has been markedly influenced by changes in the winter-time weather. Figure 4 highlights the August rainfall totals since 1970, together with the mean monthly surface weather variables. The precipitation time-series shows a clear step change just after 1980 and a steady increase thereafter. Apart from a subtle increase in mean wind speed, and a decrease in surface pressure, no striking meteorological changes are apparent in the remaining surface weather variables. However, a more careful analysis of the near surface $(10 \mathrm{~m})$ wind record highlights differences between the pre-1982 and post-1982 climate. Figure 5a shows the wind-rose analysis for both periods, with the 1982-2008 data in pale grey overlaying the 1970-81 record in black.

There are two aspects of the wind-rose diagrams that are of note. First, the number of observations of northwesterly wind has decreased, the number of observations of a strong $\left(10-20 \mathrm{~ms}^{-1}\right)$ north to northwesterly wind has increased, and the number of calm days has decreased. The changes in the number of calm days and north to northwesterly flow is even more marked when the $1982-2008$ period is compared with the earlier records from 1948-69 (fig. 5b). The reduction in the number of calm days at the island would partly explain the increasing mean wind speeds (figs 3,4 ), as would the increases in the strong north to northwesterly flow. Furthermore, the increasing north to nor thwesterly flow is indicative of a more meridional pattern and suggestive of more active rain-bearing frontal systems sweeping up to the island.

To further investigate cyclonic activity at the island the three-hourly surface pressure record was analysed for cyclonic changes. The second derivative of the pressure with respect to time $\left(\delta=\mathrm{d}^{2} \mathrm{~s} / \mathrm{p} / \mathrm{dt}^{2}\right)$ was analysed. A positive value of $\delta$ implies falling pressure followed by rising pressure, or more precisely a low pressure event passing the island. The number of these events exceeding threshold values was counted for each month. Figure 6 shows the monthly counts for $\delta=0.2$ $\mathrm{hPa} / \mathrm{h}^{2}$, (a moderate change), and $\delta=0.4$ $h \mathrm{~Pa} / \mathrm{h}^{2}$, (a strong change), for the period January 1970 to December 2008, with the annual means overlaid on the charts (thicker lines). A clear upward trend in the number of moderate changes crossing the island has occurred, with an increase from around 10 events per month to nearly 15 per month. With the strong events, there is a subtle increase from around two events per month to just under three. Clearly the inference from the Macquarie Island wind

FIG. 2 - Annual total precipitation for Macquarie Island for the period 1948-2008. 
FIG. 3 - The Macquarie Island meteorological record for the period 1970-2008, with annual total precipitation (top panel), annual mean wind speed (second panel), annual mean temperature and dewpoint temperature (third panel) and annual mean surface level pressure (bottom panel).

FIG. 4 - The Macquarie Island meteorological record for August for the period 1970-2008, with monthly total precipitation (top panel), monthly mean wind speed (second panel), monthly mean temperature and dew-point temperature (third panel) and monthly mean surface level pressure (bottorn panel).

FIG. 5-Macquarie Island near-surface wind rose comparison for $(A)$ the period 1970-81 and the period 1982-2008; and (B) the period 1948-69 and the period 1982-2008.
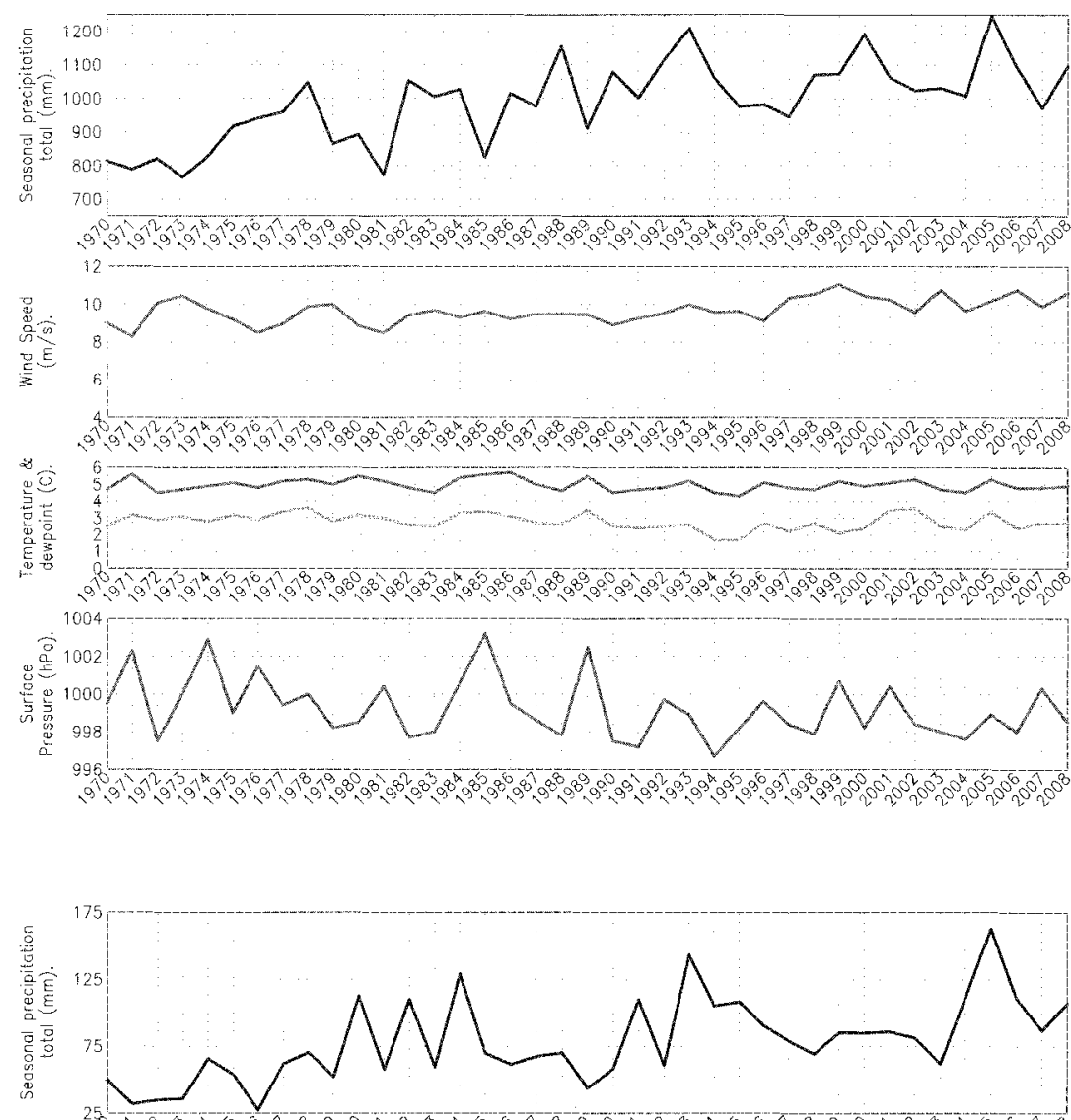

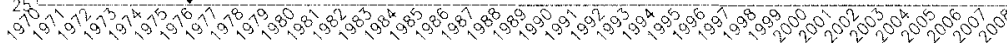
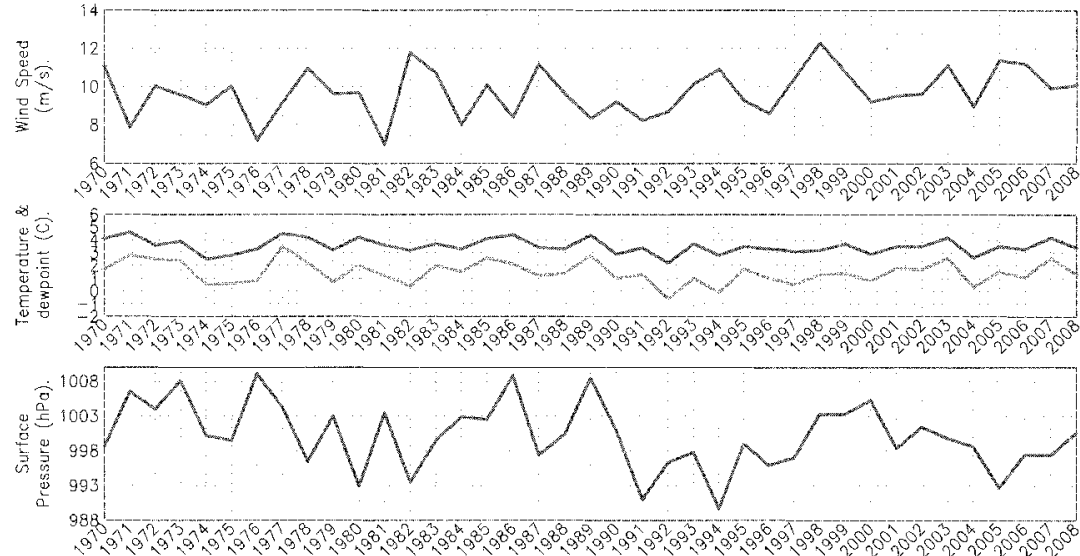

Wind Rose data for station wmo $=94998$ (macca-1970-81) $0.5 \overline{5.10} 10.2020 .3030 .40>40 \mathrm{~m}$

$10 \%$ of Observations

(34322 Observations use

\section{aromonts.}

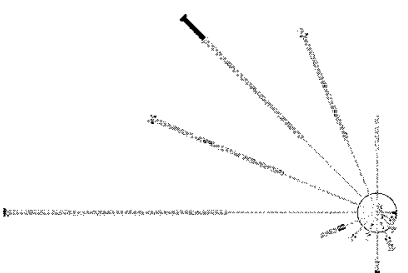

(Sc093 Observations used.)
$1 / 4 / 1948$ to 31/12/1969

Wind Rose dala for siation wmo $=94998$ (macca-1948-69)

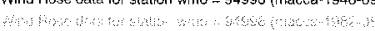
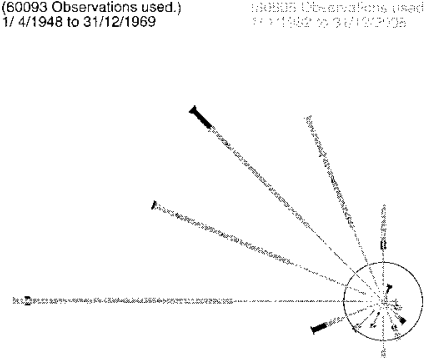

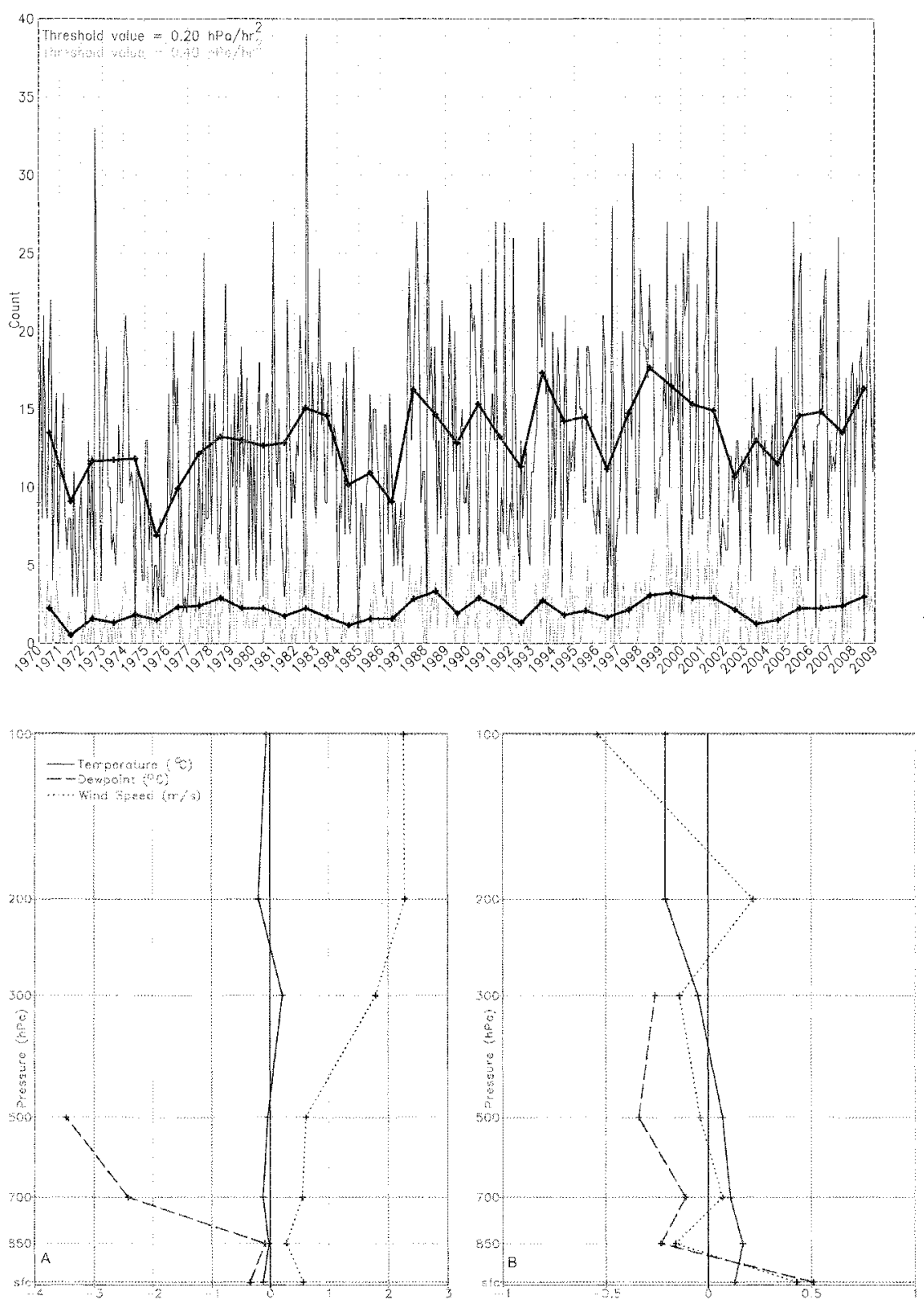

FIG. 6 - Significant pressure change events at Macquarie Island, expressed as the number of events in each month where the second order derivative of surface pressure with respect to time exceeded threshold values of 0.20 and $0.40 \mathrm{hPal}$ $h^{2}$. The annual mean monthly count for both threshold values is also plotted as thicker dark lines.
FIG. 7 - Upper air anomalies for temperature, dew-point temperature and wind speed for (A) the period 1982-2008 minus the period 1970 to 1981; and (B) the period 2000-2008 minus the period 1990-99.

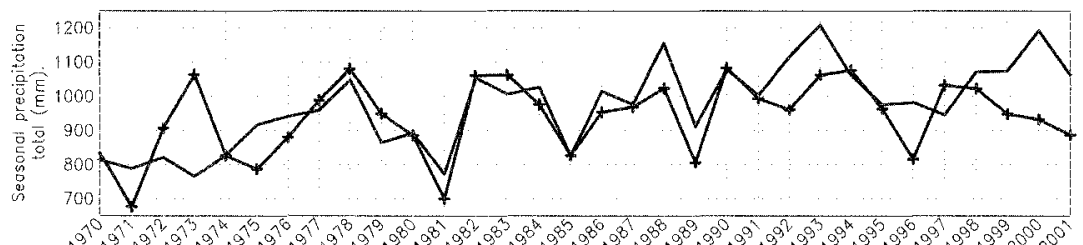

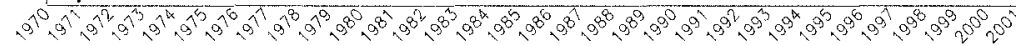

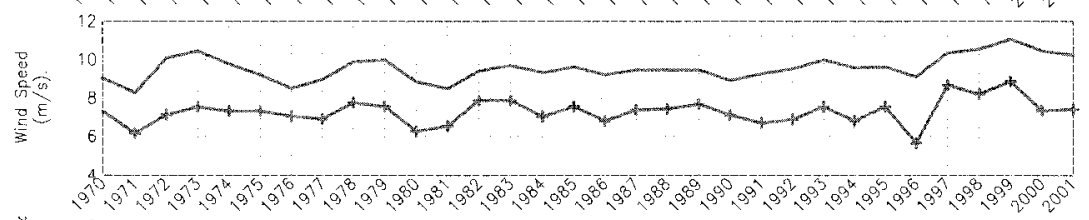

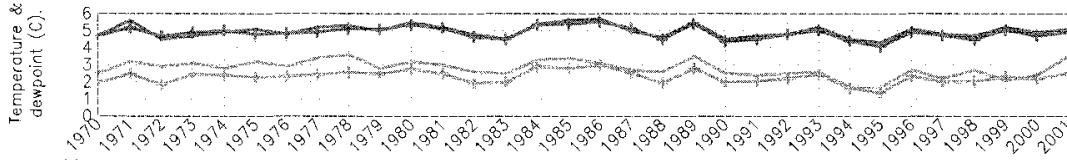

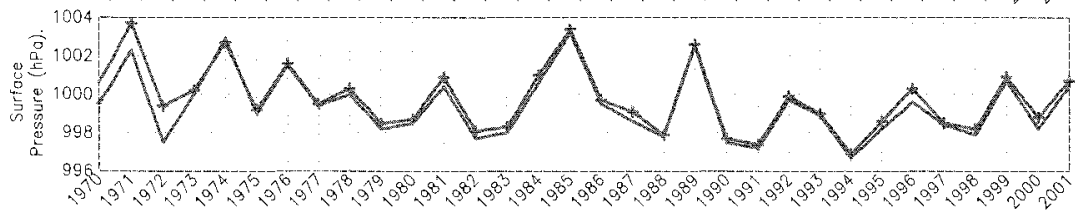

FIG. 8 - A comparison of annual mean data from the Macquarie Island observations record and data from the closest grid point in the ERA 40 re-analysis dataset $\left(55^{\circ} \mathrm{S} 160^{\circ} \mathrm{E}\right.$, with annual total precipitation (top panel), mean uind speed (second panel), temperature and dew-point temperature (third panel) and surface pressure (bottom panel). 
and pressure record is that the number of cyclonic events crossing the island has increased, resulting in an increase in the number of larger precipitation events.

Meteorological changes at Macquarie Island have not been confined to near the surface. An analysis of radiosonde data from 1970-2008 also shows clear changes throughout the troposphere and stratosphere. Figure 7 a shows the changes in the mean upper air wind speed, temperature and dewpoint fields post-1980. The temperature signal is very weak with a very slight cooling in the lower troposphere below $500 \mathrm{hPa}$, and slight warming in the upper troposphere. The stratosphere (above $300 \mathrm{hPa}$ ) has shown a slight cooling. Wind speeds have increased throughout the atmosphere, but most notably in the stratosphere. The dew-point record only extends to $500 \mathrm{hPa}$ for the earlier part of the period; however, there has been a dramatic drying in the free atmosphere between 850 and $500 \mathrm{hPa}$ (approximately 5000-18 500 feet), which is unlikely to be associated with humidity sensor changes. Figure $7 \mathrm{~b}$ highlights the changes from the decade pre-2000 to post-2000, where a small temperature increase in the lower troposphere is evident, as is a continued drying in the free atmosphere. Tropospheric wind speeds haven't altered dramatically, apart from a slight increase in near-surface wind speed.

In summary, an analysis of the weather record at Macquarie Island has highlighted a shift in the weather regime around 1982 , to a pattern that is slightly windier, and drier through the free atmosphere compared with the pre-1982 climate. The higher precipitation totals are consistent with an increase in significant cyclonic weather events, occurring in a background atmosphere that is drier, with the increases most notable during the winter months. The increased mean wind speed, coupled with the drier atmosphere has probably led to an increase in surface evaporation and a drying of the island surface, although there are no evaporation records from the island to verify this. The increases in wind speed and decreases in free atmosphere dew-points appear to agree with the trends noted by Fyfe (2003). However, the increase in precipitation appears to be at odds with his findings. An analysis of ERA- 40 re-analysis data in the following section attempts to address this issue in defining the regional nature of the sub-Antarctic zone.

\section{ERA-40 RE-ANALYSIS DATA OVER THE SUB-ANTARCTIC}

The European Centre for Medium Range Weather Forecasting (ECMWF) has undertaken a re-analysis project (ERA40) to produce an analysis dataset of the global atmosphere spanning the period 1957-2002. These analyses are generated using all available surface, upper air and satellite observations, and assimilated within a modern Numerical Weather Prediction model to produce a four-dimensional grid of weather elements spanning the global troposphere and stratosphere, four times a day for the full period (Uppala et al. 2005). The ERA40 re-analysis dataset is just one of several datasets available to researchers, with the other most notable being the NCEPNCAR re-analysis project (Kalnay et al. 1996). However, several studies have highlighted issues with the NCEP/ NCAR re-analysis data at high southern latitudes (Marshall 2003, Bromwich \& Fogt 2004) and noted the improved representation of high southern latitudes within the ERA40 data. Both studies highlighted the significant improvement in the re-analyses post-1979 as a result of the introduction of satellite data into the analysis system, and Bromwich et al. (2004) further noted that the quality of the ERA 40 analyses did improve from 1970 onwards.

To highlight the accuracy of the ERA40 re-analyses, monthly means of near-surface weather parameters from the analysis grid-point closest to Macquarie Island were extracted for the period 1970-2002 and compared to the observations from Macquarie Island (fig. 8). Several key points are of note from the comparison. First, the ERA40 precipitation analysis does not increase as much as observed over the 32 year period, although there is an upward trend. Second, the re-analysis wind speeds are lower than observed. However, the remaining variables of temperature, dew-point and surface pressure are remarkably well-structured within the re-analysis data. Observations of precipitation are not assimilated by the re-analysis system but are generated through parameterisation schemes within the numerical weather prediction (NWP) model. These parameterisation schemes may not necessarily capture all of the physical process involved in the hydrological cycle. For example, the resolution of the re-analysis system is such that Macquarie Island is not resolved and the grid point used within the system is entirely oceanic, meaning that no orographic influences on the precipitation would be present. The weaker wind speeds within the model may be a reflection of the relatively coarse horizontal resolution of the model (approximately $125 \mathrm{~km}$ ), or the parameterisation scheme used to reduce the model wind speeds down to the $10 \mathrm{~m}$ level. However, the trends in the wind speed are very well reproduced over the 32-year period.

To further investigate the dynamical reasons behind the shift in Macquarie Island weather post-1981 the long-term differences in the ERA 40 near-surface wind and pressure were compared for the period 1970-81, and 1982-2002. Figure 9 shows the difference field of wind speed (grey shaded) between the two periods, with the contour analysis showing the surface pressure differences. In broad terms there is a notable increase in the speed of the westerly flow in the subAntarctic zone $\left(50^{\circ} \mathrm{S}-60^{\circ} \mathrm{S}\right)$ over much of the hemisphere,

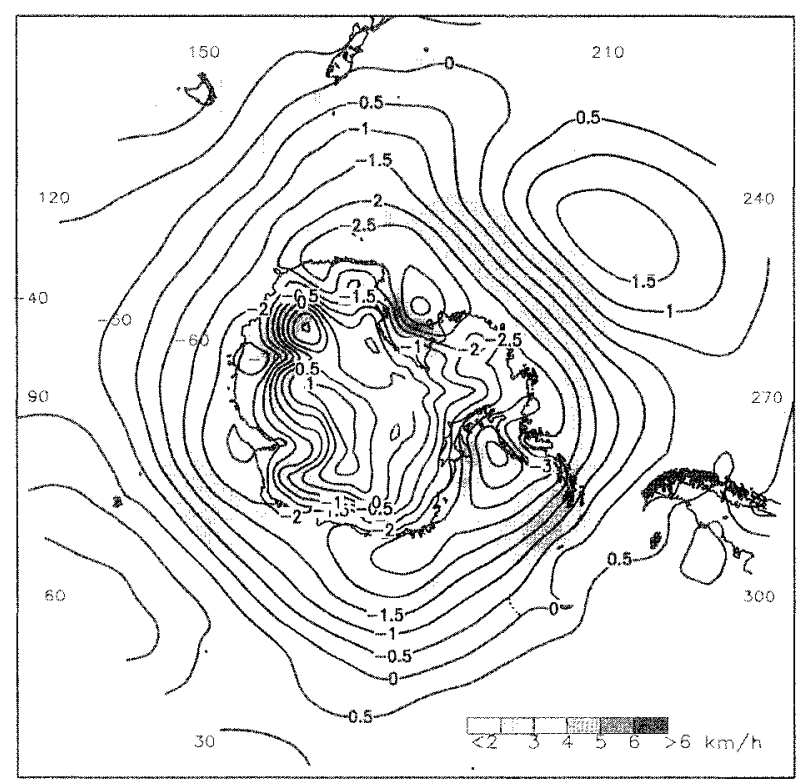

FIG. 9 - ERA40 difference pattern in near-surface wind speed (greyscale shaded plot) and sea level pressure (contour analysis) for the period 1982-2002 minus the period 1970-81, over the mid- to bigh latitudes of the Southern Hemisphere. 

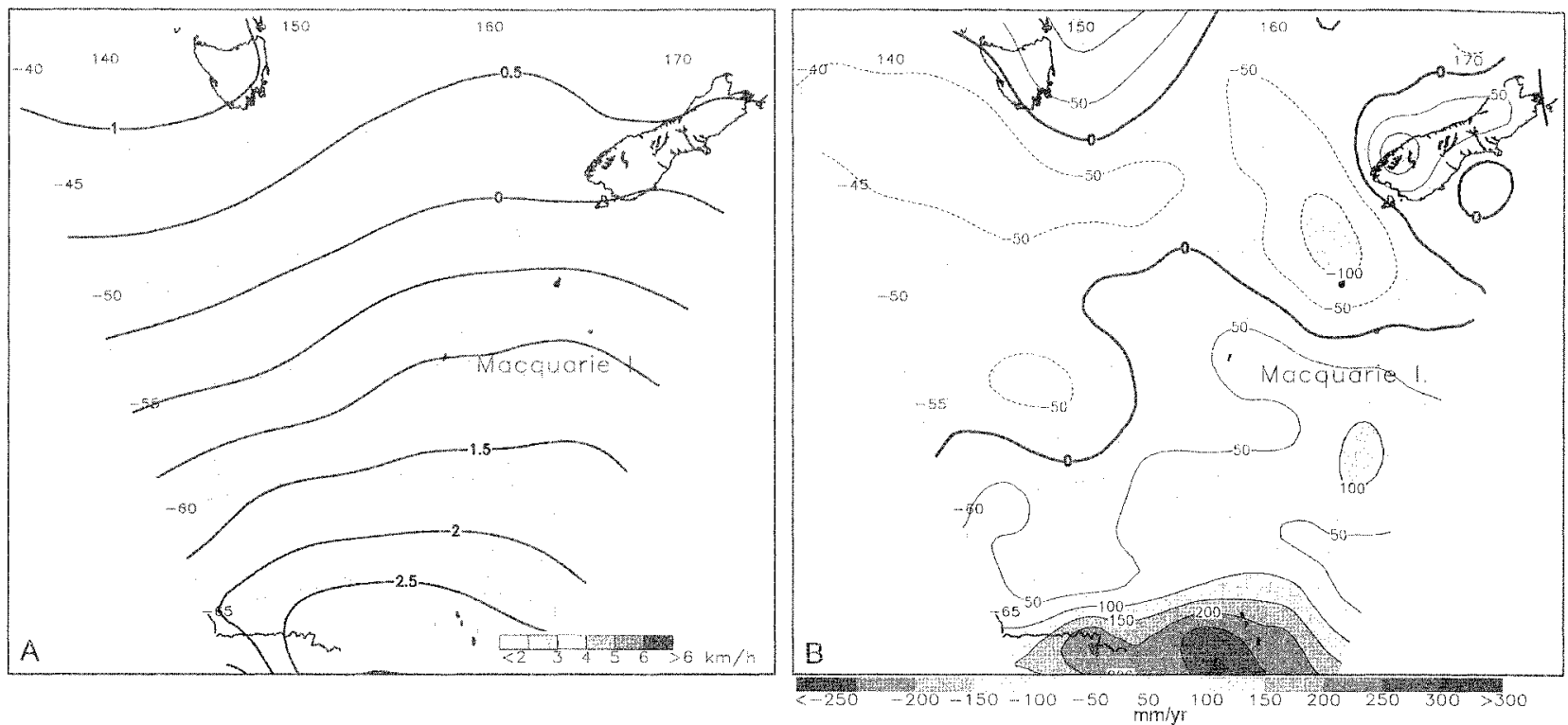

FIG. 10 - ERA40 difference patterns over the Macquarie Island sector for (A) near surface wind speed (greyscale shaded plot) and sea level pressure (contour analysis) for the period 1982-2002 minus the period 1970-81; and (B) precipitation for the period 1982-2002 minus the period 1970-1981.
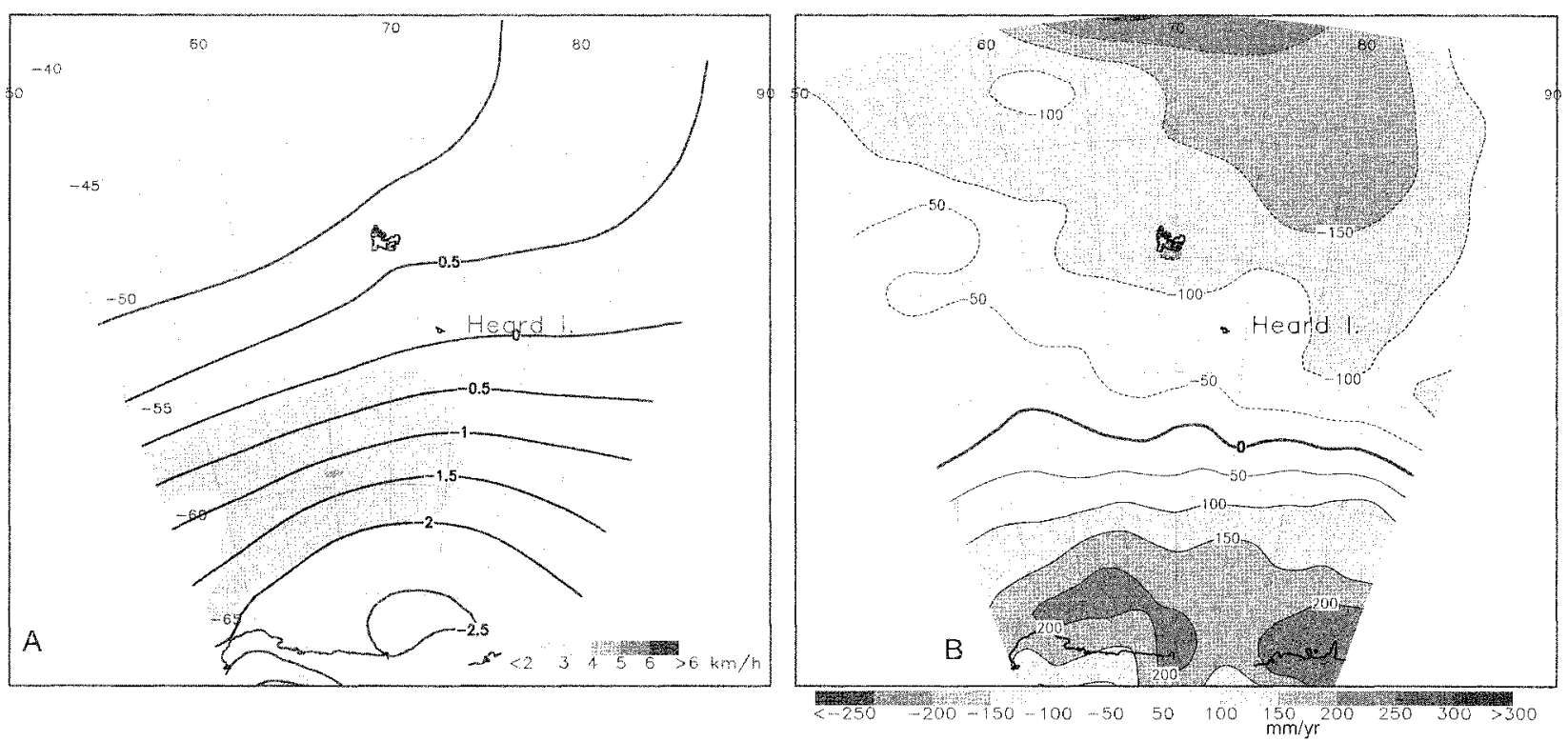

FIG. $11-E R A 40$ difference patterns over the Heard Island sector for $(A)$ near surface wind speed (greyscale shaded plot) and sea level pressure (contour analysis) for the period 1982-2002 minus the period 1970-81; and(B) Precipitation for the period 1982-2002 minus the period 1970-81. 
although less so immediately to the south of Australia. The increasing westerly flow is consistent with the studies (e.g., Fyfe 2003) showing an increase in the Southern Annular Mode (SAM) index (Marshall 2003) over the past several decades. In the longitudes of Macquarie Island the most notable feature in figure 9 is the strong trough of low pressure in the westerly flow extending out of the Antarctic trough near Cape Adare $\left(170^{\circ} \mathrm{E}\right)$ and northward just east of New Zealand. Figure 10a highlights the Macquarie Island area of figure 9 and the shift to more cyclonic flow over the island is quite evident. The difference field in precipitation is shown in figure $10 \mathrm{~b}$ and the associated increase in precipitation associated with the increase in cyclonic activity is evident over the island and to the southeast and south.

The regional differences in changes over the past two decades shown in figure 9 are quite marked, and the need to be careful in making generalised statements about changes across the entire sub-Antarctic obvious. Figure 11 shows the same information as in figure 10 but for the area around Heard Island, and quite clearly the changes at Heard Island are significantly different to those at Macquarie Island. Wind speeds have increased slightly and the flow may even have become slightly more cyclonic as at Macquarie Island. However, Heard Island has experienced slight increases in pressure and the annual precipitation totals have fallen quite significantly in the ERA40 re-analyses, consistent with the generalised statements of changes in the sub-Antarctic by Fyfe (2003), and comparable analyses using the NCEPNCAR reanalysis data (http://www.bom.gov.au/cgi-bin/ climate/change/trendmaps.cgi).

\section{FUTURE TRENDS IN THE SUB-ANTARCTIC}

Little may be found in the literature specifically addressing the issues of climate variability and change in the sub-Antarctic. From an analysis of transient climate change scenarios spanning 1850-2100 based on the Global Climate Model (GCM) from the Canadian Centre for Climate Modelling and Analysis (CCCma), Fyfe (2003) concluded that under a "business as usual" carbon emissions scenario, the number of sub-Antarctic Ocean $\left(40^{\circ} \mathrm{S}-60^{\circ} \mathrm{S}\right)$ cyclones would continue to fall and be at $30 \%$ of early twentieth-century numbers by the end of the century, with the depth of these cyclones also diminishing. The analysis also concluded that the number of Antarctic Ocean cyclones would increase which is consistent with a poleward shift in the baroclinic zone and increasing westerly flow through the southern regions of the sub-Antarctic. The analysis looked at sub-Antarcticwide statistics but, as previously mentioned, the ERA40 re-analysis data show quite strong regional differences across the sub-Antarctic.

In the IPCC AR4 a multi-model approach was taken to assess likely atmospheric changes out to the end of the twenty-first century. In an analysis of the mid-to high carbon emissions scenario (A1B) AR4 (chapter 10, IPCC 2007) also concluded that the observed increasing trend in the SAM index would continue out to the end of the century. However, the report differed in the expected changes in precipitation across the sub-Antarctic, highlighting significant regional and seasonal differences. Figure 10.9 from the report (see link to chapter 10 under http://www.ipcc.ch/ipccreports/ ar4-wg $1 . h \mathrm{hm}$ ) highlights the expected changes between the multi-model means for the period 2080-99 relative to 1980-99. During the sub-Antarctic summer months a statistically significant reduction in precipitation is expected from the sub-tropics southward to around $50^{\circ} \mathrm{S}$, although with a distinct three-wave pattern with areas of increased precipitation along the east coast of South America, south of Madagascar and in the longitudes of Macquarie Island and New Zealand, although not at a statistically significant level. Statistically significant summer-time increases in precipitation are expected between $55^{\circ} \mathrm{S}$ and $65^{\circ} \mathrm{S}$. During the winter months the multi-model ensemble mean shows a statistically significant increase in precipitation over much of the sub-Antarctic and, notably, highlights local maxima in the increase in the Macquarie Island longitudes. The winter-time pressure trends in figure 10.9 from the report highlight a deepening of the polar trough immediately to the south of Macquarie Island, with an increase in surface pressure over Australia and the north island of New Zealand, giving a trend towards a strengthening winter-time long wave trough just west of Macquarie Island.

\section{CONCLUSIONS}

An analysis of the Macquarie Island observational record has shown a clear trend in increasing precipitation and a modest increase in wind speed on the island over the past four decades, consistent with the expected response to a globally changing climate under increased greenhouse gases. Re-analysis data from the ERA40 project has captured the changing subAntarctic environment, characterised by increasing westerly flow in the mid-latitudes with a corresponding drying, increased cyclonic activity to the south of the sub-Antarctic resulting in regional increases in precipitation over parts of the sub-Antarctic, particularly during winter. Analysis of the multi-model output for the A1B scenario from the IPCC AR4 climate projections suggests a continuation of these trends over the twenty-first century although the details of these changes over the sub-Antarctic are not well resolved.

The sub-Antarctic needs a more careful analysis of the past and current climate to better understand the atmospheric dynamics and the likely responses of the system over the coming decades to climate change forcing.

\section{ACKNOWLEDGEMENTS}

The ERA40 re-analysis data were supplied from the European Centre for Medium Range Weather Forecasting (ECMWF). Thanks to Ian Barnes-Keoghan for assistance in verifying the surface observations from Macquarie Island.

\section{REFERENCES}

Bromwich, D.H. \& Fogt, R.L. 2004: Strong trends in the skill of the ERA-40 and NCEP-NCAR reanalyses in the high and midlatitudes of the Southern Hemisphere. Journal of Climate 17: 4603-4619.

Fyfe, J.C. 2003: Extratropical Southern Hemisphere cyclones: harbingers of climate change? Joumal of Climate 16: 2802-2805.

IPCC 2007: Climate Change 2007: The Physical Science Basis. Contributions of Working Group I to the Fourth Assessment Report of the Intergovernmental Panel on Climate Change [Solomon, S., D. Qin, M. Manning, 
Z. Chen, M. Marquis, K. B. Averyt, M. Tignor and H. L. Miller (eds)]. Cambridge University Press, Cambridge, UK and New York NY, USA: 996 pp.

Kalnay, E. Kanamitsu, M., Kistler, R., Collins, W., Deaven, D., Gandin, L., Iredell, M., Saha, S., White, G., Woollen, J., Zhu, Y., Leetmaa, A., and Reynolds, R. 1996: The NCEP/NCAR 40-year Re-analysis Project. Bulletin of the American Meteorological Society 77: 437-71.

Marshall, G.J. 2003: Trends in the Southern Annular Mode from observations and reanalyses. Joumal of Climate 16: $4134-4143$

Pendlebury, S.F. \& Barnes-Keoghan, I.P. 2007: Climate and climate change in the Sub-Antarctic. Papers and Proceedings of the Royal Society of Tasmania 141(1): 67-81.
Uppala, S.M., Kållberg, P.W., Simmons, A.J., Andrac, U., da Costa Bechtold, V., Fiorino, M., Gibson, J.K., Haseler, J., Hernandez, A., Kelly, G.A., Li, X., Onogi, K., Saarinen, S., Sokka, N., Allan, R.P., Andersson, E., Arpe, K., Balmaseda, M.A., Beljaars, A.C.M., van de Berg, L., Bidlot, J., Bormann, N., Caires, S., Chevallier, F., Dethof, A., Dragosavac, M., Fisher, M., Fuentes, M., Hagemann, S., Hólm, E., Hoskins, B.J., Isaksen, L., Janssen, P.A.E.M., Jenne, R., McNally, A.P., Mahfouf, J.-F., Morcrette, J.-J., Rayner, N.A., Saunders, R.W., Simon, P., Sterl, A., Trenberth, K.E., Untch, A., Vasiljevic, D., Viterbo, P. \& Woollen, J. 2005: The ERA-40 re-analysis. Quarterly Joumal Royal Meteorological Society 131: 2961-3012.doi:10.1256/qj.04.176

(accepted 6 October 2009) 